\title{
Polyethylenimine nanofibrous adsorbent for highly effective removal of anionic dyes from aqueous solution
}

\author{
Yao $\mathrm{Ma}^{1,2}$, Bowu Zhang ${ }^{1^{*}}$, Hongjuan $\mathrm{Ma}^{1}$, Ming $\mathrm{Yu}^{1}$, Linfan $\mathrm{Li}^{1}$ and Jingye $\mathrm{Li}^{{ }^{*}}$
}

\begin{abstract}
We prepared a nanofibrous adsorbent for anionic dye removal from aqueous solution by electrospinning a modified polyethylenimine (m-PEI) and polyvinylidene fluoride (PVDF) blend. The electrospun nanofibrous adsorbent was confirmed to be a nanoscale, porous material with a positively charged surface; these characteristics are quite beneficial for anionic contaminant adsorption. Experimental adsorption of an anionic dye, methyl orange (MO), demonstrates that this adsorbent can rapidly remove MO from aqueous solution; its maximum adsorption capacity was $633.3 \mathrm{mg} \mathrm{g}^{-1}$, which is much higher than that of previously reported adsorbents. After immersion in a basic solution, the adsorbent was well regenerated and showed good recyclability. The adsorption performance of the nanofibrous adsorbent is greatly influenced by the temperature, initial MO concentration, and $\mathrm{pH}$ of the solution. We further found that MO adsorption onto the adsorbent can be described well by the pseudo-second-order kinetic model and Langmuir isotherm model. Weber-Morris plots suggested that the adsorption of MO onto the nanofibrous mat was affected by at least film diffusion and intraparticle diffusion. This study indicates that nanofibrous PEI composite mats could be promising for treatment of wastewater containing anionic dye.
\end{abstract}

Keywords: nanofibrous adsorbent, anionic dye, electrospinning, polyethylenimine

\section{INTRODUCTION}

Industrial wastewater, a legacy of the industrial revolution and its conflict between environmental capacity and human expansion, continues to be a problem for governments, businesses, the scientific community, and ordinary people worldwide [1,2]. Reducing wastewater discharge and decontaminating water resources are the two acknowledged strategies for prevention and remediation of water pollution, respectively $[3,4]$. Technology for removing contaminants from water is crucial to the success of either strategy. Wastewater containing organic dyes is one of the most common byproducts of the paint manufacture, dyeing, cosmetics, textile, paper, leather, and other industries, and it can poison the environment and endanger the safety of drinking water and foodstuffs $[5,6]$. Therefore, removal of organic dye from water is a major project for the development of a sustainable society [7].

Adsorption is recognized as one of the most promising methods because of its high effectiveness, low cost, and popularity $[8,9]$. Polymeric adsorbents are widely used as materials for the removal of organic or inorganic contaminants from water or air because of their advantages such as high flexibility in the design of structures and properties; chemical stability in harsh environments, including strong acidic, alkaline, salty, and oxidizing solutions; feasible regeneration; and thermal durability [9-11]. Polyethylenimine (PEI) has a high amine density and accessible primary amine sites on the chain ends, which act as desirable building blocks for the construction of adsorbents. For instance, many excellent $\mathrm{CO}_{2}$ adsorbents have been prepared by integrating PEI into porous materials, including silica [12], mesoporous carbon [13], titanate [14], polymeric supports [15], and other metal oxide nanocomposites [16]. In addition, because of the high positive charge density on the protonated PEI backbone or side chains, PEI-based adsorbents exhibit good adsorption capacity for acidic gas or anionic materials such as polyanions and negatively charged organic or inorganic matter, including various anionic dyes [16-19].

Electrospinning is an effective approach to prepare ultrafine fibers; it uses an electrostatic force from an external high-voltage electrical field between a spinneret and a grounded collector to draw very fine (typically micro- to nanoscale) fibers from a liquid droplet [20]. The ultrafine fibers produced by electrospinning have very high specific

\footnotetext{
${ }^{1}$ Shanghai Institute of Applied Physics, Chinese Academy of Sciences, Shanghai 201800, China

${ }^{2}$ University of Chinese Academy of Sciences, Beijing 100049, China

*Corresponding authors (emails: zhangbowu@foxmail.com (Zhang B); jingyeli@sinap.ac.cn (Li J))
} 
surface areas. Visual microscopy also reveals many mesopores and micropores over an assembly of ultrafine fibers (the so-called electrospun mat). These structural features make electrospun materials quite suitable for activities that require a high degree of physical contact such as providing active sites for physicochemical interactions (e.g., catalysis and adsorption) [21-23] or the capture of small particulate materials by physical entanglement (i.e., air filtration) [24-26]. In our previous work, we prepared a nanofibrous, porous amidoxime-based adsorbent by electrospinning for uranium extraction from seawater and successfully improved the utility of the functional group, amidoxime, for coordination with uranyl ions [27].

Here, we present a simple route to prepare a cationic nanofibrous adsorbent by electrospinning using branched PEI (b-PEI) as the starting material for the removal of anionic dyes from water. Because of its excellent water solubility and poor mechanical properties, b-PEI was modified by introducing a methacrylate group via a ring-opening reaction between the primary amine of b-PEI and epoxy of glycidyl methacrylate (GMA) before electrospinning. It was then blended with polyvinylidene fluoride (PVDF) in $\mathrm{N}, \mathrm{N}$-dimethyl formamide (DMF) to provide the feed solution for electrospinning. The modified PEI, methacrylated polyethylenimine (m-PEI), could be cross-linked by UV light irradiation during electrospinning, which provides the m-PEI fibers with good water resistance [28]. In addition, PVDF could provide admirable mechanical strength to the resultant nanofibrous adsorbent, namely, the m-PEI/ PVDF composite mat. In this study, a typical anionic dye, methylene orange (MO), was used as the target pollutant of water. The MO removal performance was explored by adsorption batch assays. The influence of the temperature, initial $\mathrm{MO}$ concentration, and $\mathrm{pH}$ of the solution on $\mathrm{MO}$ adsorption was also evaluated together with the relationship between the MO adsorption capacity and adsorption time. Further, the kinetic behavior of MO adsorption on the PEI-based nanofibrous adsorbent was studied to determine the removal rate and rate-controlling step of the adsorption process.

\section{EXPERIMENTAL SECTION}

\section{Materials and reagents}

DMF, MO, sodium hydroxide $(\mathrm{NaOH})$, hydrochloric acid $(\mathrm{HCl})$, and other chemicals of analytical grade were purchased from Sinopharm Chemical Reagent Co., Ltd., China. b-PEI (molecular weight, MW 10,000) and GMA were purchased from Sigma-Aldrich Co., Ltd., USA. PVDF powder (MW 420,000) was purchased from Solvay Chemicals Co., Ltd., Belgium. All chemicals were used without further purification.

\section{Synthesis of methacrylated polyethylenimine (m-PEI)}

The m-PEI was synthesized following a previous report [28]. The detailed procedure is as follows. The b-PEI was dissolved in DMF in a glass vial that was bathed in ice water during the reaction. 4-Methoxyphenol was added to the b-PEI solution at $10 \mathrm{mmol} \mathrm{L}^{-1}$ to prevent homopolymerization of GMA, and GMA was added dropwise to the b-PEI solution under magnetic stirring. Then the mixture was continuously stirred and shielded from light during synthesis. The reaction of b-PEI with GMA is shown in Scheme 1. After $24 \mathrm{~h}$, the methacrylated b-PEI was then precipitated from the DMF by $n$-hexane, leaving the free and self-polymerized GMA in solution. The white residue was washed with $n$-hexane three times and then vacuum filtered, dried, and characterized by Fourier transform in-

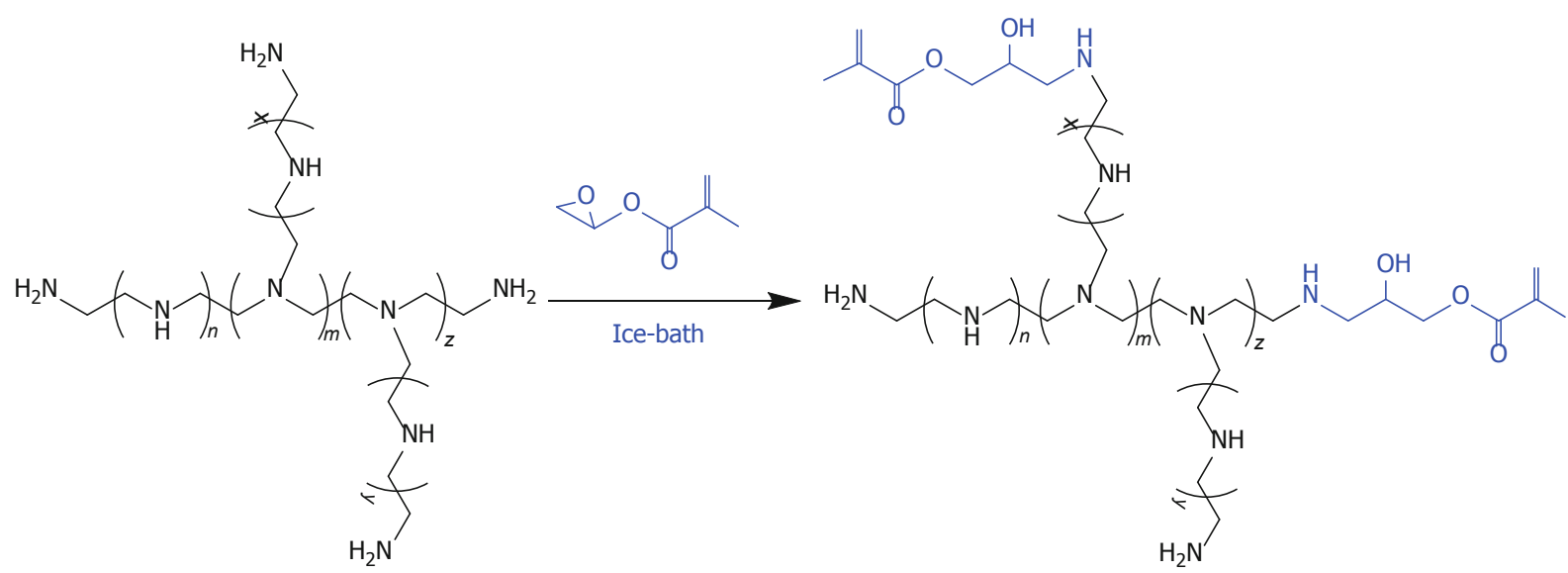

Scheme 1 Schematic diagram of the ring-opening reaction between b-PEI and GMA. 
frared (FT-IR) spectroscopy and thermogravimetric analysis (TGA).

\section{Preparation of $\mathrm{m}-\mathrm{PEI} / \mathrm{PVDF}$ nanofibrous mats}

Purified m-PEI is very easily cross-linked, which makes it difficult to re-dissolve it in DMF to prepare the feed solution for electrospinning. To avoid this situation, the above synthesis mixture was immediately mixed with various amounts of PVDF solution in DMF after reaction without any purification and subsequently electrospun under the following conditions: a feeding rate of $0.3 \mathrm{~mL} \mathrm{~h}^{-1}$, a voltage of $17 \mathrm{kV}$, and a distance of $10 \mathrm{~cm}$ between the needle and the rotating drum collector. Electrospinning was performed at room temperature under illumination by an energy-saving lamp. The resultant fibrous mat was dried in vacuum at $40^{\circ} \mathrm{C}$ overnight to remove residual solvent. To remove the unmodified b-PEI from the fibrous mat, the mat was immersed in abundant pure water at $40^{\circ} \mathrm{C}$ for $48 \mathrm{~h}$ and then dried in vacuum at $40^{\circ} \mathrm{C}$.

The $\mathrm{m}$-PEI content of the $\mathrm{m}$-PEI/PVDF composite mats was determined by microwave digestion in a MARS $6^{\text {m }}$ Microwave Digestion System, which was reported in our previous work [27]. The actual m-PEI content of the mats, $x(\%)$, can be calculated as follows:

$$
x(\%)=\left(W_{\mathrm{o}}-W_{\mathrm{d}}\right) / W_{\mathrm{o}} \times 100 \%,
$$

where $W_{\mathrm{o}}(\mathrm{g})$ and $W_{\mathrm{d}}(\mathrm{g})$ are the weights of the m-PEI/ PVDF composite mats before and after microwave digestion, respectively. Three composite mats were prepared with various ratios of PVDF and $\mathrm{m}$-PEI in the mixed solution. After water immersion and oven-drying, the m-PEI contents of these composite mats were $35.8 \%, 41.9 \%$, and $49.5 \%$, respectively. The weight change of these composite mats and a contrasting sample (b-PEI/PVDF mat) are listed in Table S1 (Supplementary information), which confirms that cross-linking of the GMA modifier immobilizes PEI on the mat and enhances its water stability.

\section{Porosity testing of $\mathrm{m}-\mathrm{PEI} / \mathrm{PVDF}$ composite mats}

Brunauer-Emmett-Teller (BET) nitrogen adsorption and mercury porosimetry are generally the most popular methods of characterizing the porosity of porous materials. Owing to the special features of the pore structure, these two methods are not suitable for determining the porosity of electrospun mats $[29,30]$. Here, an alternative method based on the inherent densities of m-PEI and PVDF, and the apparent density of the m-PEI/PVDF composite mats, is applied [27,31]. The inherent densities of $\mathrm{m}-\mathrm{PEI}$ and PVDF can be obtained by measuring the volume and weight of dense films of $\mathrm{m}$-PEI and PVDF, respectively.
Similarly, the apparent density of the m-PEI/PVDF composite mats can be calculated by measuring the weight and volume of the mats. Therefore, the porosity $p(\%)$ of the electrospun $\mathrm{m}$-PEI/PVDF composite mats was calculated using the following equation through derivation:

$$
p(\%)=\frac{\rho_{\mathrm{i}} \rho_{\mathrm{F}}-\rho_{\mathrm{i}} \rho_{\mathrm{M}}-x \rho_{\mathrm{M}}\left(\rho_{\mathrm{F}}-\rho_{\mathrm{i}}\right)}{\rho_{\mathrm{i}} \rho_{\mathrm{F}}} \times 100 \%,
$$

where $\rho_{\mathrm{i}}$ and $\rho_{\mathrm{F}}$ represent the inherent densities of $\mathrm{m}$-PEI and PVDF, respectively, and $\rho_{M}$ is the apparent density of the $\mathrm{m}-\mathrm{PEI} / \mathrm{PVDF}$ composite mats.

\section{Adsorption experiments}

The obtained m-PEI/PVDF composite mats were applied to batch adsorption experiments in aqueous MO solution. An initial solution with an MO concentration of 1000 $\mathrm{mg} \mathrm{L}^{-1}$ was prepared and diluted to different concentrations for the adsorption experiments. The effects of the initial concentration and $\mathrm{pH}$ value of the $\mathrm{MO}$ solution and the adsorption temperature on the adsorption performance of the composite mats were investigated under the following conditions: $0.5 \mathrm{~g} \mathrm{~L}^{-1}$ of mat in solution, thermostatic water bath, and a shaking speed of $120 \mathrm{rpm}$. The adsorption kinetics was studied by adding the composite mat to $\mathrm{MO}$ solutions $\left(50 \mathrm{mg} \mathrm{L}^{-1}\right)$ shaken continuously for $7 \mathrm{~h}$ in a thermostatic water bath oscillator at $25^{\circ} \mathrm{C}$ and $120 \mathrm{rpm}$ until equilibrium.

The concentrations of residual MO in the solutions were determined by a spectrophotometric method using a U3900 UV-vis spectrophotometer. Because the maximum adsorption peak appears at $464 \mathrm{~nm}$, we measured the absorbance at $464 \mathrm{~nm}$ of MO standard solutions with concentrations ranging from 0.25 to $12 \mathrm{mg} \mathrm{L}^{-1}$ and plotted a linear calibration curve (see Fig. S1 in Supplementary information) to determine the residual MO concentration of the solutions after adsorption. Considering the concentration range for the linear curve, all the sampling solutions were diluted to a suitable concentration before measurement. Thus, the amount of MO adsorbed per unit of adsorbent at instant time $\left(q_{\mathrm{i}}\right)$ or equilibrium $\left(q_{\mathrm{e}}\right)$ (i.e., the adsorption capacity of the mats) was calculated as follows:

$$
\begin{aligned}
& q_{\mathrm{i}}=\left(C_{\mathrm{o}}-C_{\mathrm{i}}\right) V / W, \\
& q_{\mathrm{e}}=\left(C_{\mathrm{o}}-C_{\mathrm{e}}\right) V / W,
\end{aligned}
$$

where $C_{\mathrm{o}}, C_{\mathrm{i}}$, and $C_{\mathrm{e}}$ are the concentration of the initial $\mathrm{MO}$ solution and the $\mathrm{MO}$ concentration at instant time and adsorption equilibrium, respectively. $V(\mathrm{~L})$ is the volume of MO solution, and $W(\mathrm{~g})$ is the weight of the adsorbent. 


\section{Desorption and recyclability of composite mats}

Desorption of the m-PEI/PVDF composite mats was performed by one-step, two-step, and three-step methods. The one-step method was performed as follows. After adsorption in $100 \mathrm{~mL}$ of $\mathrm{MO}$ solution $\left(50 \mathrm{mg} \mathrm{L}^{-1}\right)$, the m-PEI/ PVDF nanofibrous mat $(50 \mathrm{mg}$ ) was immersed in $100 \mathrm{~mL}$ of $0.1 \mathrm{~mol} \mathrm{~L}^{-1} \mathrm{NaOH}$ solution for $1 \mathrm{~h}$, and the MO concentration in the leaching solution was determined to evaluate the desorption ratio.

In the two-step method, the $100 \mathrm{~mL}$ of $\mathrm{NaOH}$ solution $\left(0.1 \mathrm{~mol} \mathrm{~L}^{-1}\right)$ was split into two equal volumes, and the adsorbed mat was immersed in the first $50 \mathrm{~mL}$ of $\mathrm{NaOH}$ solution for $30 \mathrm{~min}$ and then immersed again in a fresh $50 \mathrm{~mL}$ of $\mathrm{NaOH}$ solution for $30 \mathrm{~min}$. The MO concentrations of the leaching solutions used in each step were also determined to evaluate the desorption ratio. Similarly, in the three-step method, the $100 \mathrm{~mL}$ of $\mathrm{NaOH}$ solution $(0.1$ mol L ${ }^{-1}$ ) was trisected, and the mat was immersed sequentially in these three equal volumes of $\mathrm{NaOH}$ solution for 20 min each.

The recyclability test was performed as follows. A $50 \mathrm{mg}$ composite mat sample was added to $100 \mathrm{~mL}$ of $50 \mathrm{mg} \mathrm{L}^{-1}$ $\mathrm{MO}$ solution for $7 \mathrm{~h}$ and then taken out, rinsed thrice with pure water, and desorbed in $100 \mathrm{~mL}$ of $\mathrm{NaOH}$ solution $(0.1$ mol L ${ }^{-1}$ ) for $1 \mathrm{~h}$. Subsequently, the desorbed mat was removed from the desorption solution, added to $100 \mathrm{~mL}$ of $50 \mathrm{mg} \mathrm{L}{ }^{-1} \mathrm{MO}$ solution for $7 \mathrm{~h}$, and desorbed again as described above. The recycling experiment was repeated ten times.

\section{Characterization and method}

The FT-IR spectra of b-PEI, m-PEI, PVDF, and an m-PEI/ PVDF composite mat were obtained using a Bruker Optics TENSOR 27 FT-IR spectrometer over a range of 4000-600 $\mathrm{cm}^{-1}$ in attenuated total reflection (ATR) mode. TGA was performed on a Q500 Thermogravimetric Analyzer (TA Instruments, USA). The samples were heated from 50 to $700^{\circ} \mathrm{C}$ at a rate of $10^{\circ} \mathrm{C} \mathrm{min}^{-1}$ under a nitrogen atmosphere. The morphology of the composite mats was characterized using scanning electron microscopy (SEM; JSM-6700F, JEOL, Japan) after they were sputtered with a 10-nm-thick gold layer in vacuum. The zeta potential was measured on a Delsa ${ }^{\mathrm{Tm}}$ Nano Zeta Potential and Submicron Particle Size Analyzer (Beckman Coulter Inc., USA) to study the surface potential of $\mathrm{m}$-PEI/PVDF composite mats in solutions with different $\mathrm{pH}$ values. The composite mats were positioned in a flat flow cell with a groove. Sodium phosphate buffer solutions with different $\mathrm{pH}$ values were injected into the cell using disposable syringes. After the air bubble was expelled, the cell was placed in the analyzer, and the zeta potential was determined. Before each measurement, the electrophoresis cell was thoroughly washed and rinsed with deionized water.

\section{RESULTS AND DISCUSSION}

\section{Preparation of $\mathrm{m}-\mathrm{PEI} / \mathrm{PVDF}$ nanofibrous adsorbents}

Fig. 1a shows that a very obvious new peak around 1720 $\mathrm{cm}^{-1}$ (indicating the carboxyl group) appears in the FT-IR spectrum of $\mathrm{m}$-PEI but not in that of pristine b-PEI. This result confirms that GMA was introduced on the b-PEI chains successfully. In addition, the broad bands around 1590 and $1640 \mathrm{~cm}^{-1}$, which correspond to N-H deformation vibration and primary amine, respectively, and the peak at $1469 \mathrm{~cm}^{-1}$, which is assigned to the stretching vibration absorption of $\mathrm{C}-\mathrm{N}$ bonds [32,33], still appear in the FT-IR spectrum of the electrospun m-PEI/PVDF composite mat, which was purified by abundant pure water. This result indicates that the modification of b-PEI was effective for enhancing its water resistance and immobilizing the PEI chains in the composite mat. Regarding the weak peak due to carboxyl groups in the FT-IR spectra of the m-PEI/PVDF mat, the carboxyl group signal is thought to have decreased dramatically because of massive PVDF blending. In light of the sampling thickness in ATR mode, it could also be attributed to inward migration of hydrophobic GMA and outward migration of PEI chains during water immersion of the composite mat.

Fig. $1 \mathrm{~b}$ shows the thermal decomposition behavior of $\mathrm{m}$-PEI, PVDF, and m-PEI/PVDF nanofibrous mats with different $\mathrm{m}$-PEI contents. Owing to the good hygroscopicity of PEI, considerable weight loss occurred between 100 and $175^{\circ} \mathrm{C}$, which can be ascribed to vaporization of water contained in m-PEI [34], although it was dried in an oven. The sharp weight loss of m-PEI between 260 and $392^{\circ} \mathrm{C}$ is ascribed to decomposition of PEI [35]. The weight loss from 392 to $439^{\circ} \mathrm{C}$ can be attributed to random chain scission of the cross-linked GMA on the end of m-PEI [36]. The onset pyrolysis temperature of PVDF is as high as $400^{\circ} \mathrm{C}$ [37], and when it was blended with $\mathrm{m}$-PEI and electrospun into $\mathrm{m}-\mathrm{PEI} / \mathrm{PVDF}$ nanofibrous mats, its thermal stability clearly declined. The decomposition of PVDF would start at about $280^{\circ} \mathrm{C}$. Similarly, the decomposition of PEI chains also occurred early, starting at $185^{\circ} \mathrm{C}$. This is probably because the nanoscale structure of the $\mathrm{m}-\mathrm{PEI} /$ PVDF nanofibrous mats is much smaller than the particle sizes of m-PEI and PVDF powder; thus, it enhances the thermal transmission to molecules and the volatility of the pyrolysis products, easily changing the thermal composition of the mats. This phenomenon has also been found 

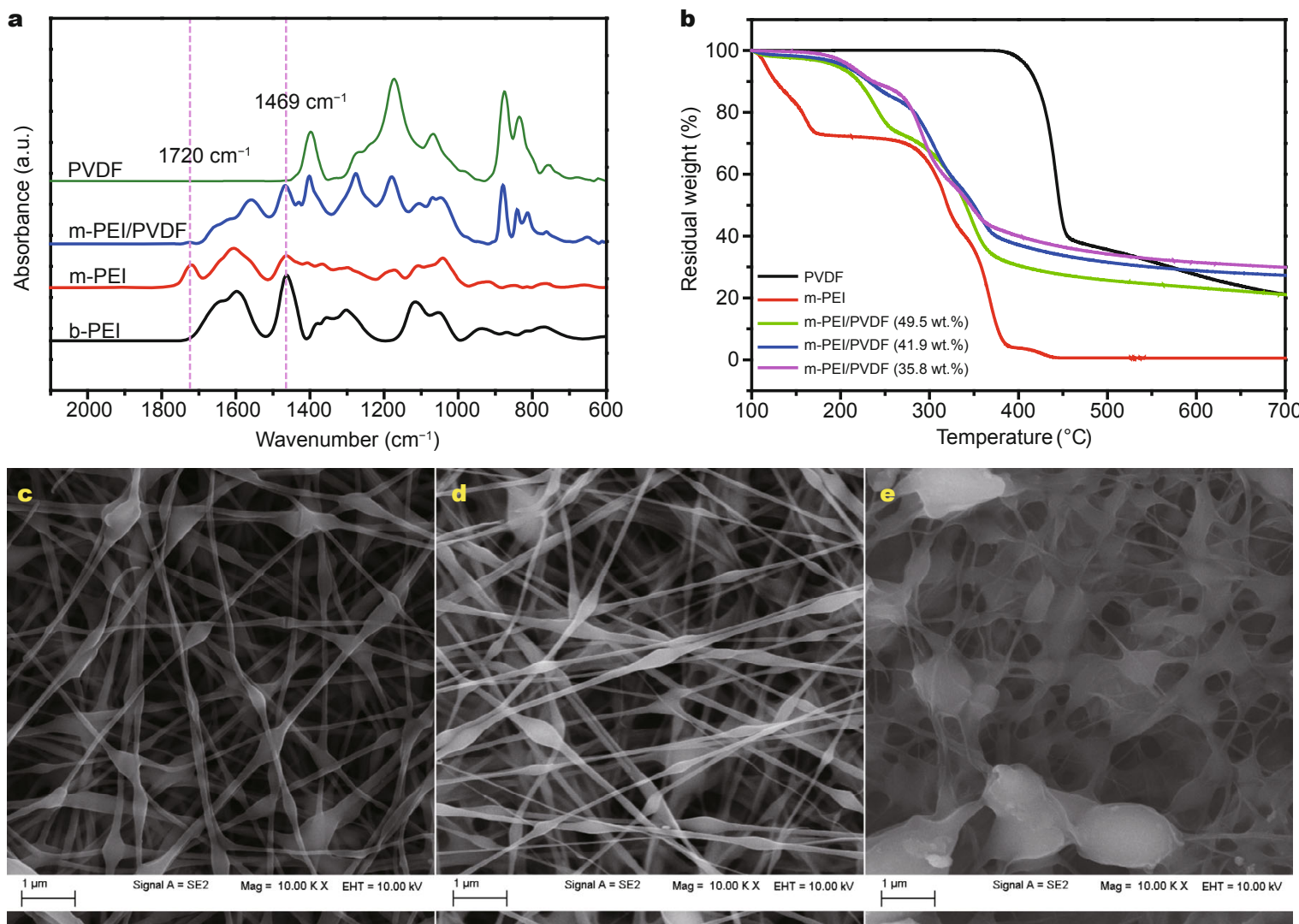

Figure 1 (a) FT-IR spectra of neat b-PEI, m-PEI, PVDF, and m-PEI/PVDF nanofibrous mat; (b) TGA profiles of pure m-PEI, PVDF powder, and m-PEI/ PVDF nanofibrous mats with different m-PEI contents; SEM images of immersed m-PEI/PVDF mat with m-PEI contents of (c) $35.8 \%$, (d) $41.9 \%$, and (e) $49.5 \%$.

in the thermal decomposition of polyvinyl alcohol (PVA)/ chitosan and PVA/cyanobacterial extracellular polymeric substance blended nanofibrous membranes [38]. The degradation profiles of the three nanofibrous mats with different $\mathrm{m}$-PEI contents are very similar except for the residual weight loss.

The micromorphology of three nanofibrous mats with different $\mathrm{m}$-PEI contents was investigated by SEM. Fibers with diameters of 50-200 $\mathrm{nm}$ were interwoven in a nanofibrous network with many mesopores and micropores (Figs 1c-e, S2). Spindles consisting of concatenated nanofibers were also found in the network, and the spindle size and content increase with increasing m-PEI content, especially in the nanofibrous mat containing $49.5 \%$ PEI. In fact, the viscosity and surface tension of the low-molecular-weight b-PEI (MW 10,000) used here are insufficient for electrospinning to form fibers even after modification with GMA. Therefore, blending with PVDF in solution is performed to increase the surface tension and chain entanglement. Figs 1c-e suggests that the PVDF content should exceed $50 \mathrm{wt} . \%$ in order to achieve fine $\mathrm{m}$-PEI/PVDF blend fibers.
Additionally, cross-linking of GMA on the side chain of b-PEI is also helpful for enhancing the water resistance of $\mathrm{m}$-PEI and explains why $\mathrm{m}$-PEI remains in the mats after abundant water immersion for $48 \mathrm{~h}$.

The porosities of the $\mathrm{m}$-PEI/PVDF composite mats were calculated using Equation (2) with the inherent density of $\mathrm{m}$-PEI and PVDF and the apparent density of the mats [27,31]. The porosities of $\mathrm{m}-\mathrm{PEI} / \mathrm{PVDF}$ composite mats containing $35.8 \%, 41.9 \%$, and $49.5 \%$ PEI are $86.6 \%, 89.1 \%$, and $64.4 \%$, respectively. These results show excellent agreement with the micromorphological features of the composite mats in Figs 1c-e.

\section{Adsorption ability of m-PEI/PVDF nanofibrous mats}

Fig. 2a shows the UV-vis absorption spectra and color change of the MO solution at different adsorption times. The absorbance at the $464 \mathrm{~nm}$ peak decreased with increasing adsorption time, and almost no absorbance remained after $180 \mathrm{~min}$. Further, the color of the MO solution gradually became lighter with increasing adsorption time and finally became pellucid, which was consistent with the 

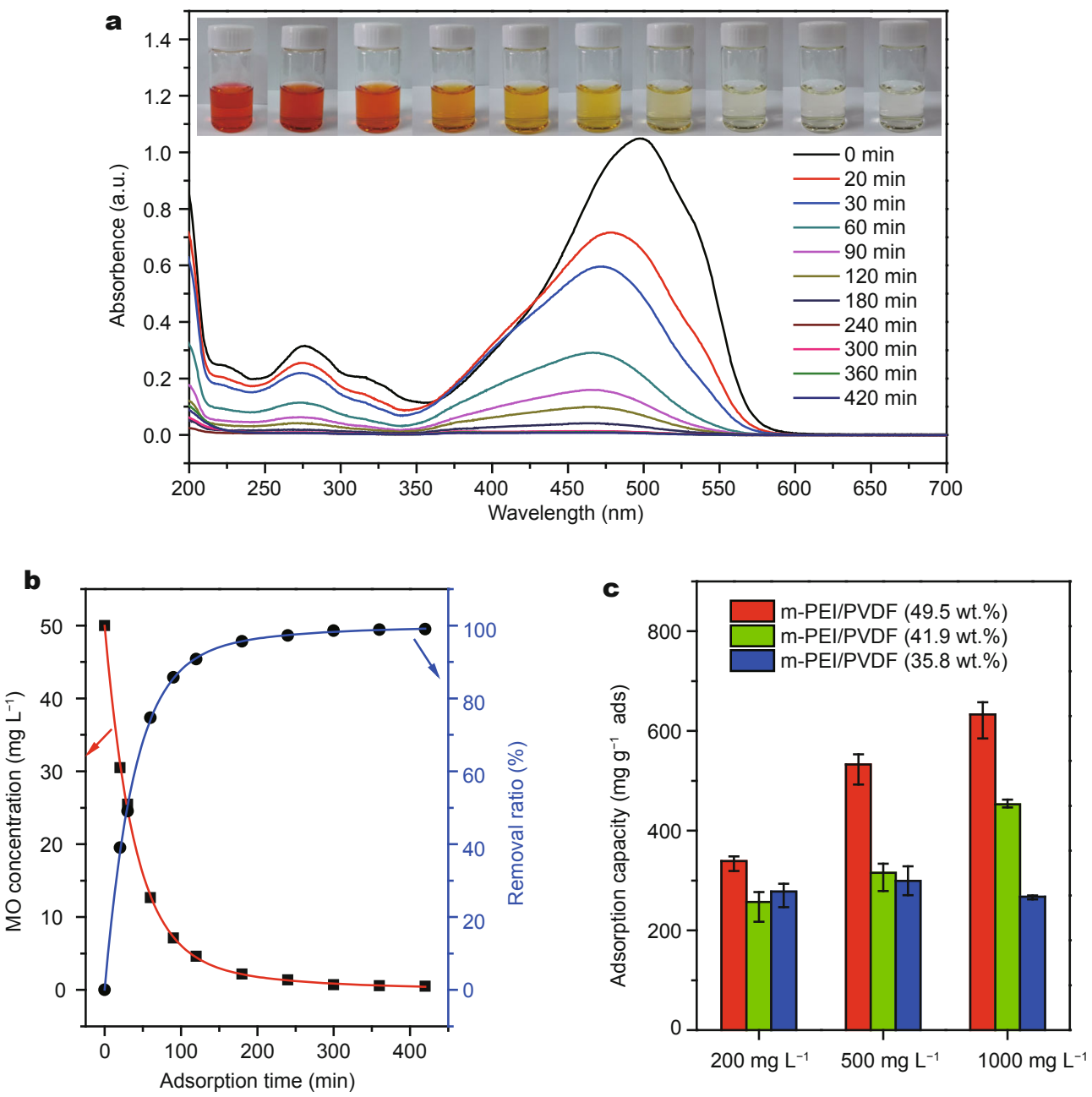

Figure 2 (a) UV-vis spectra and color change of $\mathrm{MO}$ solution after adsorption for different times and (b) concentration of $\mathrm{MO}$ solution and removal ratio at different times during adsorption (initial concentration: $50 \mathrm{mg} \mathrm{L}^{-1}$, adsorbent dosage: $0.5 \mathrm{~g} \mathrm{~L}^{-1}$, temperature: $25^{\circ} \mathrm{C}$, $\mathrm{pH} 3$ ); (c) maximum adsorption capacity of electrospun $\mathrm{m}-\mathrm{PEI} / \mathrm{PVDF}$ nanofibrous mats with different $\mathrm{m}-\mathrm{PEI}$ contents (temperature: $25^{\circ} \mathrm{C}$, adsorbent dosage: $0.5 \mathrm{~g} \mathrm{~L} \mathrm{~L}^{-1}$, adsorption time: $24 \mathrm{~h}, \mathrm{pH} 7)$.

UV-vis absorption spectra. Fig. 2b illustrates that the concentration of the residual MO solution is nearly zero after $180 \mathrm{~min}$ of adsorption, and the removal ratio of $\mathrm{MO}$ is almost $100 \%$ after $180 \mathrm{~min}$. These results demonstrate that the $\mathrm{m}-\mathrm{PEI} / \mathrm{PVDF}$ nanofibrous mat is a good adsorbent for rapid removal of $\mathrm{MO}$ from water.

To assess the adsorption ability of m-PEI/PVDF nanofibrous mats with different $\mathrm{m}$-PEI contents, the mats were added to MO solutions with initial concentrations of 200, 500 , and $1000 \mathrm{mg} \mathrm{L}^{-1}$ for $24 \mathrm{~h}$ (Fig. 2c). Because $\mathrm{MO}$ is prone to precipitation in solutions with high concentration and low $\mathrm{pH}$, these experiments were conducted in solution at $\mathrm{pH}$ 7. All of the mats present a high maximum adsorption capacity of more than $250 \mathrm{mg} \mathrm{g}^{-1}$. Further, the adsorbent with $35.8 \% \mathrm{~m}$-PEI content reaches approximately the same adsorption capacity for all of the MO solutions, but those with $41.9 \%$ and $49.5 \% \mathrm{~m}$-PEI content reach much higher adsorption capacities of 425 and $633 \mathrm{mg} \mathrm{g}^{-1}$, respectively, in the $1000 \mathrm{mg} \mathrm{L}^{-1} \mathrm{MO}$ solution, which is much higher than that of many novel adsorbents previously reported (see Table 1). Mats with a higher m-PEI content have more active sites for $\mathrm{MO}$ adsorption, but considering that the difference in $\mathrm{m}$-PEI content is relatively small and the porosity of the mats is inversely proportional to the m-PEI content, there should be another reason for the outstanding adsorption ability of composite mats containing $49.5 \% \mathrm{~m}$-PEI. PEI is known to be a hydrophilic and water-soluble macromolecule. After modification with GMA, the m-PEI can remain in water and keep its location on the fibers, but is still easily swollen. This structure under aqueous conditions is high- 
Table 1 Comparison of the maximum adsorption capacity of MO onto various adsorbents

\begin{tabular}{|c|c|c|c|c|c|}
\hline Adsorbent & $q_{\max }\left(\mathrm{mg} \mathrm{g}^{-1}\right)$ & $\mathrm{pH}$ & Temperature $(\mathrm{K})$ & Dosage $\left(\mathrm{g} \mathrm{L}^{-1}\right)$ & Ref. \\
\hline $\mathrm{Mg}-\mathrm{Al} \mathrm{LDH}$ & 148.3 & 6.5 & 298 & 0.4 & [39] \\
\hline $\mathrm{NH}_{2}-\mathrm{MWCNTs}$ & 185.5 & 2 & 273 & 0.2 & {$[40]$} \\
\hline Activated carbon & 238.1 & natural $\mathrm{pH}$ & 283 & 1 & [41] \\
\hline rGO-CNT-PPD hybrid & 294 & 3 & 298 & 0.1 & {$[42]$} \\
\hline Core-shell Cu@ $\mathrm{Cu}_{2} \mathrm{O}$ & 344.84 & 5.67 & 293 & 0.16 & {$[43]$} \\
\hline Chitosan $/ \mathrm{Al}_{2} \mathrm{O}_{3} /$ magnetite & 416 & natural $\mathrm{pH}$ & 298 & 0.4 & [44] \\
\hline $\mathrm{H}-\delta-\mathrm{MnO}_{2}$ nanoparticles & 427 & natural $\mathrm{pH}$ & 293 & 0.2 & {$[45]$} \\
\hline m-PEI/PVDF nanofibrous mat & 633.3 & natural $\mathrm{pH}$ & 298 & 0.5 & Present work \\
\hline
\end{tabular}

Abbreviations: LDH, layered double hydroxide; rGO, reduced graphene oxide; CNT, carbon nanotube; MWCNTs, multi-walled CNTs; PPD, p-phenylenediamine.

ly favorable for diffusion and adsorption of MO onto the mats. Therefore, the porosity of the nanofibrous mats determined under dry conditions could not indicate the real adsorption performance of the adsorbents.

A series of systematic experiments were performed to examine the MO adsorption on the $\mathrm{m}-\mathrm{PEI} / \mathrm{PVDF}$ nanofibrous mats in aqueous solution. Fig. 3a shows the effect of the initial MO concentration on the adsorption kinetics of the mats at $\mathrm{pH} 3$ and a temperature of $25^{\circ} \mathrm{C}$. The adsorption capacity of the dye on the mat increases with increasing initial dye concentration. The reason is the increase in the driving force of the concentration gradient with increasing initial dye concentration. Fig. 3a also shows that most of the MO is adsorbed to achieve equilibrium adsorption within $180 \mathrm{~min}$, which indicates excellent adsorption performance and rapid removal of MO from water. The adsorption experiments were conducted at four different temperatures $\left(25,35,45\right.$, and $\left.55^{\circ} \mathrm{C}\right)$, and the results are shown in Fig. 3b. The adsorption capacity did not increase with increasing temperature because the maximum capacity of the mat greatly exceeded the amount of MO in solution. However, the system reached equilibrium more quickly at higher adsorption temperatures. This result indicates the endothermic nature of the adsorption reaction of $\mathrm{MO}$ onto the $\mathrm{m}-\mathrm{PEI} / \mathrm{PVDF}$ nanofibrous mats.

The effect of the $\mathrm{pH}$ on adsorption of $\mathrm{MO}$ onto the nanofibrous mats at $25^{\circ} \mathrm{C}$ was examined. The study was done at different initial $\mathrm{pH}$ values ranging from 3.0 to 9.0 for a $50 \mathrm{mg} \mathrm{L}^{-1} \mathrm{MO}$ solution. The result (Fig. 3c) shows that the amount of $\mathrm{MO}$ adsorbed on the mat decreases as the $\mathrm{pH}$ value of the solution increases. Additionally, the time required to reach adsorption equilibrium was also reduced by decreasing the $\mathrm{pH}$ valve of the solution (Fig. S2). The effect of the $\mathrm{pH}$ on the zeta potential of the m-PEI/PVDF nanofibrous mats also exhibits the same tendency as the adsorption capacity. These results confirm that adsorp-
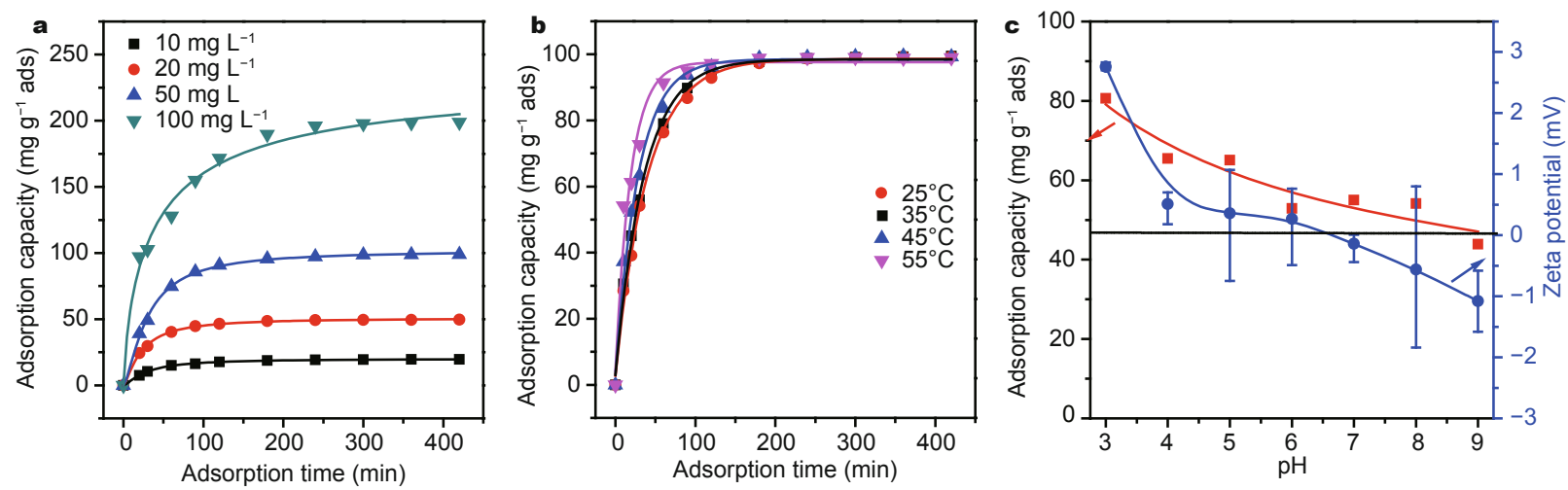

Figure 3 (a) Effect of initial MO concentration on the adsorption of MO onto m-PEI/PVDF nanofibrous mat (adsorbent dosage: $0.5 \mathrm{~g} \mathrm{~L} \mathrm{~L}^{-1}$, temperature: $25^{\circ} \mathrm{C}, \mathrm{pH} 3$ ); (b) effect of temperature on the adsorption of $\mathrm{MO}$ onto $\mathrm{m}-\mathrm{PEI} / \mathrm{PVDF}$ nanofibrous mat (initial MO concentration: $50 \mathrm{mg} \mathrm{L}^{-1}$, adsorbent dosage: $0.5 \mathrm{~g} \mathrm{~L}^{-1}, \mathrm{pH} 3$ ); (c) effect of $\mathrm{pH}$ on the adsorption of $\mathrm{MO}$ on $\mathrm{m}-\mathrm{PEI} / \mathrm{PVDF}$ nanofibrous mats and zeta potential of $\mathrm{m}-\mathrm{PEI} / \mathrm{PVDF}$ nanofibrous mat in solutions at different $\mathrm{pH}$ (initial $\mathrm{MO}$ concentration: $50 \mathrm{mg} \mathrm{L}^{-1}$, adsorbent dosage: $0.5 \mathrm{~g} \mathrm{~L}^{-1}$, temperature: $25^{\circ} \mathrm{C}$, time: $2 \mathrm{~h}$ ). 
tion is driven by the surface charge of the adsorbent. PEI is a cationic active polymer at low $\mathrm{pH}$, and the isoelectric point is about 6.5. Thus, the protonation of PEI in low-pH solution causes the surface of the composite mat to be positively charged and enhances the electrostatic interaction between $\mathrm{MO}$ and the nanofibrous mat [17].

\section{Desorption and regeneration experiment}

Because the positive charges on the nanofibrous mat drived the $\mathrm{MO}$ adsorption, $\mathrm{MO}$ was desorbed from the mat using a $\mathrm{NaOH}$ solution, which can neutralize the positive charge of PEI chains and reduce the electrostatic interaction between the MO and nanofibrous mat. In $0.1 \mathrm{~mol} \mathrm{~L}^{-1} \mathrm{NaOH}$ solution, the MO adsorbed on the nanofibrous mat can be rapidly leached when it was immersed for only a moment (see Video S1 in Supplementary information). As Fig. 4a shows, $80.8 \%$ of the MO adsorbed on the m-PEI/PVDF nanofibrous mat is leached into the $\mathrm{NaOH}$ solution. The color of the mat changed to bright red after adsorption and faded to yellow after desorption. The desorbed mat was put into another $\mathrm{MO}$ solution $\left(50 \mathrm{mg} \mathrm{L}^{-1}\right)$ and removed almost $100 \%$ of the MO in solution. After 10 cycles, the desorbed m-PEI/PVDF nanofibrous mat was still able to remove most of the MO from solution (Fig. 4b). This result demonstrates that the m-PEI/PVDF nanofibrous mat is potentially an effective and renewable adsorbent for $\mathrm{MO}$ removal. Multi-stage operation is generally favorable for enhancing the efficiency of mass transfer processes such as desorption. Therefore, two-step and three-step desorption of MO from the m-PEI/PVDF nanofibrous mat were studied by halving and trisecting, respectively, the total volume of $\mathrm{NaOH}$ solution and the desorption time used in the onestep method. Fig. $4 c$ shows that the desorption efficiency in the two-step and three-step desorption experiments is $86.7 \%$ and $87.5 \%$, respectively, which both exceed that of the one-step method. This result demonstrates that the two-step desorption process would be optimum for acceptable efficiency and a moderate amount of labor.
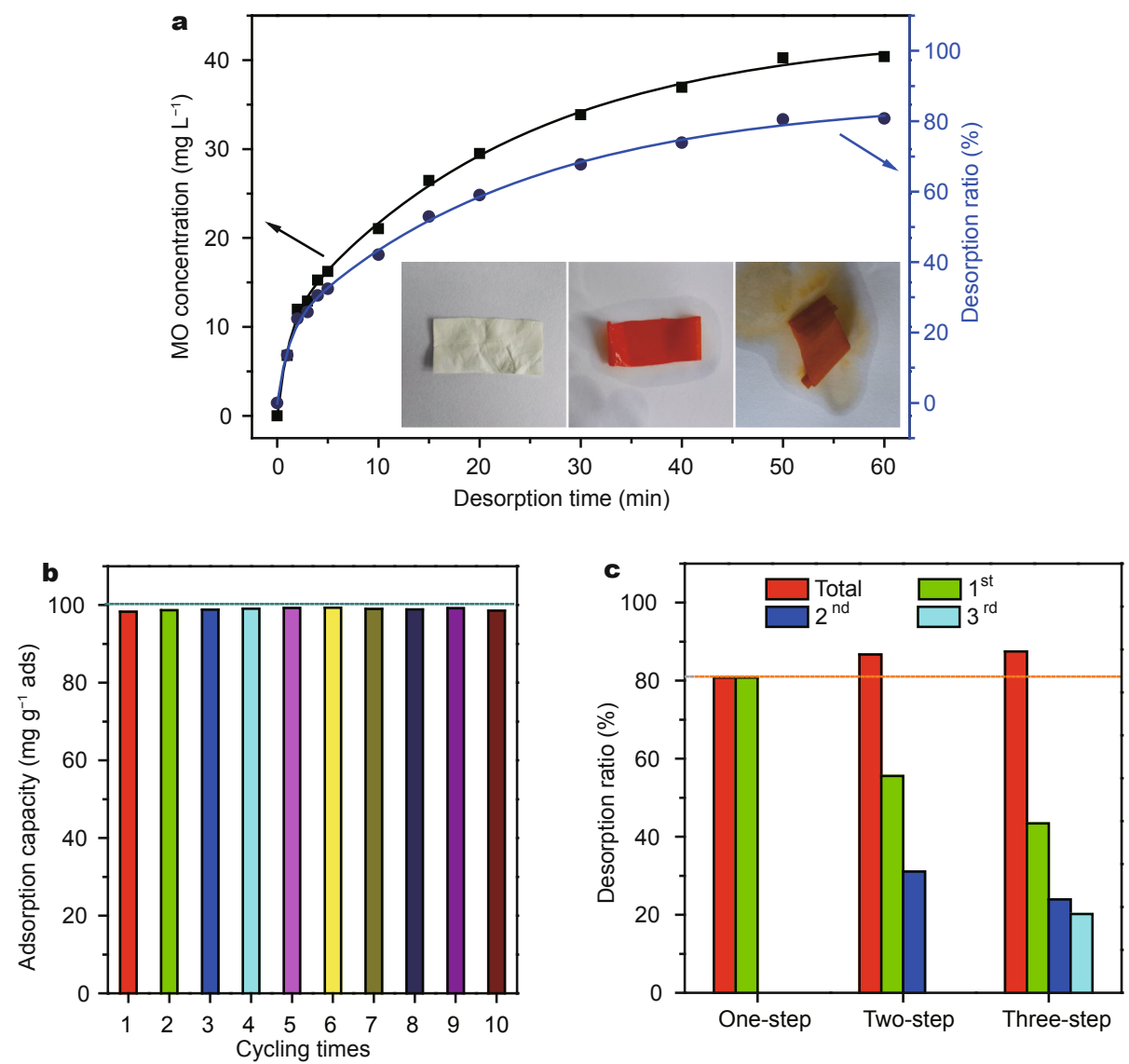

Figure 4 (a) Results of desorption experiment in $100 \mathrm{~mL}$ of $0.1 \mathrm{~mol} \mathrm{~L}^{-1} \mathrm{NaOH}$ solution; (b) regeneration and recycling adsorption experiment (initial dye concentration: $50 \mathrm{mg} \mathrm{L}^{-1}$, adsorbent dosage: $0.5 \mathrm{~g} \mathrm{~L}^{-1}$, temperature: $25^{\circ} \mathrm{C}$, contact time: $7 \mathrm{~h}$ ); (c) comparison of removal efficiency in one-step, two-step, and three-step desorption experiments. 


\section{Adsorption kinetics}

The pseudo-first-order and pseudo-second-order rate equations were employed to study the adsorption kinetics of MO on the nanofibrous mat. The linear form of the pseudo-first-order equation can be given as [39]

$$
\log \left(q_{\mathrm{e}}-q_{t}\right)=\log q_{\mathrm{e}}-\frac{k_{1} t}{2.303}
$$

The linear form of the pseudo-second-order kinetic model is expressed as [41]

$$
\frac{t}{q_{t}}=\frac{1}{k_{2} q_{\mathrm{e}}^{2}}+\frac{t}{q_{\mathrm{e}}},
$$

where $q_{\mathrm{e}}\left(\mathrm{mg} \mathrm{g}^{-1}\right)$ and $q_{t}\left(\mathrm{mg} \mathrm{g}^{-1}\right)$ are the amounts of $\mathrm{MO}$ adsorbed at equilibrium and at time $t(\mathrm{~min})$, respectively; $k_{1}\left(\mathrm{~min}^{-1}\right)$ and $k_{2}\left(\mathrm{~g} \mathrm{mg}^{-1} \mathrm{~min}^{-1}\right)$ are the pseudo-first-order and pseudo-second-order rate constants of adsorption, respectively.

The rate constants $\left(k_{1}\right.$ and $\left.k_{2}\right)$ and corresponding linear regression correlation coefficient values $\left(R^{2}\right)$ for both models were calculated using the intercept and slope of the two plots shown in Figs $5 \mathrm{a}$ and $\mathrm{b}$ and listed in Table 2. The $R^{2}$ values of the pseudo-first-order model are lower than those of the pseudo-second-order model in the entire concentration range. Moreover, the experimental equilibrium adsorption capacities $\left(q_{\text {e,exp }}\right)$ are much larger than the calculated $\left(q_{\mathrm{e}, \mathrm{cal}}\right)$ values obtained from the pseudo-first-order model but are very close to the calculated $\left(q_{\text {e,cal }}\right)$ values obtained from the pseudo-second-order model. The adsorption kinetics is clearly modeled better by the pseudo-second-order kinetic model, which has higher correlation coefficient values $\left(R^{2}>0.998\right)$ and theoretical equilibrium adsorption capacities closer to the experimental values in MO solutions with different initial concentrations. Similar kinetic behavior was also observed in adsorption of dye onto other adsorbents such as layered double hydroxide (LDH) [39], mesoporous silica [46], activated clays [47], and carbon [41]. It is also found that $k_{2}$ decreases with increasing initial MO concentration. This is attributed to the fact that the number of surface active sites on the nanofibrous mat is well in excess of the number of MO molecules at lower concentrations, and when the MO concentration is increased, the competition for surface active sites is increased, resulting in lower adsorption rates [48].

The Arrhenius activation energy of $\mathrm{MO}$ adsorption onto the $\mathrm{m}-\mathrm{PEI} / \mathrm{PVDF}$ nanofibrous mats was estimated using
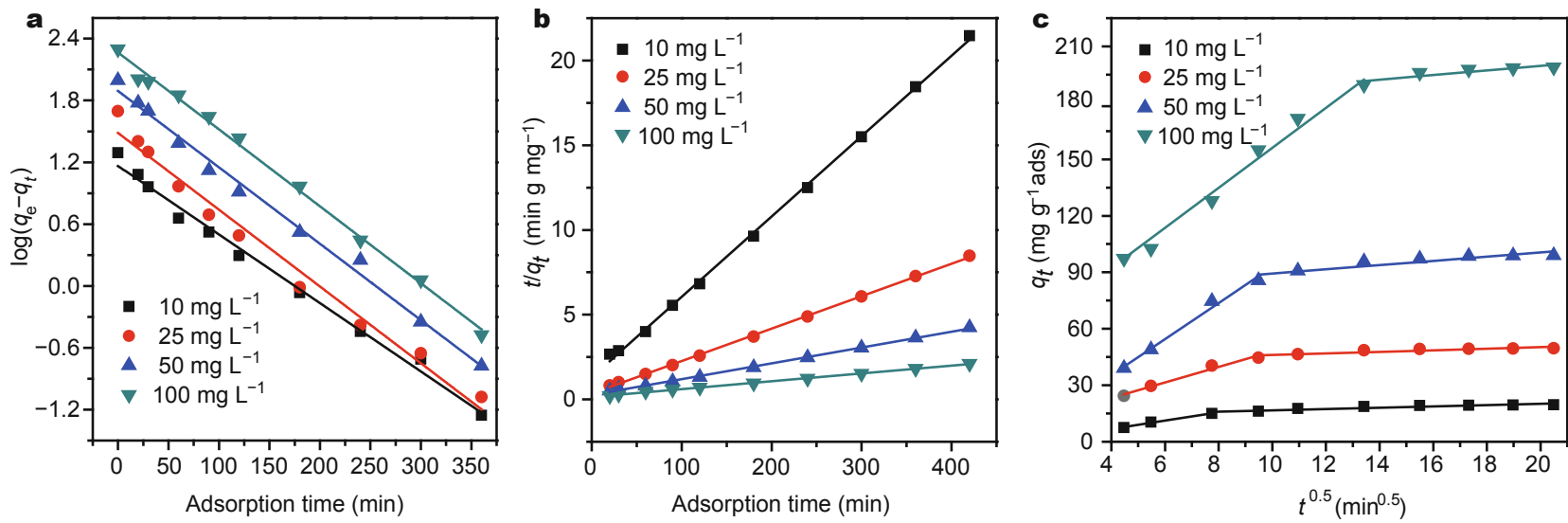

Figure 5 (a) Pseudo-second-order, (b) pseudo-second-order, and (c) intraparticle diffusion kinetic models for MO adsorption at different initial MO concentrations.

\begin{tabular}{|c|c|c|c|c|c|c|c|c|c|}
\hline \multirow{2}{*}{$\begin{array}{c}C_{0} \\
\left(\mathrm{mg} \mathrm{L}^{-1}\right)\end{array}$} & \multirow{2}{*}{$\begin{array}{c}q_{\mathrm{e}, \mathrm{exp}} \\
\left(\mathrm{mg} \mathrm{g}^{-1}\right)\end{array}$} & \multicolumn{3}{|c|}{ Pseudo-first order } & \multicolumn{3}{|c|}{ Pseudo-second order } & \multicolumn{2}{|c|}{ Intraparticle diffusion model } \\
\hline & & $q_{\mathrm{e}, \mathrm{cal}}\left(\mathrm{mg} \mathrm{g}^{-1}\right)$ & $k_{1}\left(\min ^{-1}\right)$ & $R^{2}$ & $q_{\mathrm{e}, \mathrm{cal}}\left(\mathrm{mg} \mathrm{g}^{-1}\right)$ & $k_{2}\left(\mathrm{~g} \mathrm{mg}^{-1} \min ^{-1}\right)$ & $R^{2}$ & $k_{\mathrm{id}, 1}\left(\mathrm{mg} \mathrm{g}^{-1} \min ^{-0.5}\right)$ & $k_{\mathrm{id}, 2}\left(\mathrm{mg} \mathrm{g}^{-1} \min ^{-0.5}\right)$ \\
\hline 10 & 19.56574 & 14.5912 & 0.015315 & 0.99042 & 21.08815 & 0.001716 & 0.99892 & 2.24699 & 0.34345 \\
\hline 25 & 49.59356 & 30.5288 & 0.017157 & 0.98094 & 52.21932 & 0.001063 & 0.99927 & 4.11768 & 0.41295 \\
\hline 50 & 99.00186 & 78.0046 & 0.015045 & 0.99201 & 106.8376 & 0.000344 & 0.99826 & 9.58127 & 1.12490 \\
\hline 100 & 198.8707 & 184.3954 & 0.017180 & 0.99559 & 216.4502 & 0.000147 & 0.9982 & 10.60933 & 1.22308 \\
\hline
\end{tabular}

Table 2 Kinetic parameters of adsorption of MO onto m-PEI/PVDF nanofibrous mats in aqueous solution at different initial concentrations 
the Arrhenius equation [49]:

$$
\ln k_{2}=-\frac{E_{\mathrm{a}}}{R T}+\ln A,
$$

where $R$ is the ideal gas constant $\left(8.314 \mathrm{~J} \mathrm{~mol}^{-1} \mathrm{~K}^{-1}\right), T$ is the absolute temperature $(\mathrm{K}), E_{\mathrm{a}}$ is the activation energy $\left(\mathrm{kJ} \mathrm{mol}{ }^{-1}\right.$ ), and $A$ is the Arrhenius factor. The adsorption data for $\mathrm{MO}$ at different temperatures $(25,35,45$, and $55^{\circ} \mathrm{C}$ ) (Fig. 3b) were linearly plotted as $\ln k v s .1 / T$ (Fig. S3). According to the obtained slope, $-E_{\mathrm{a}} / R$, the activation energy $E_{a}$ is $34.7 \mathrm{~kJ} \mathrm{~mol}^{-1}$, which indicates that the MO was adsorbed physically onto the nanofibrous mats [49].

To identify the diffusion mechanisms and rate controlling steps of MO adsorption onto the nanofibrous mat, the intraparticle diffusion kinetics model, which is proposed by Weber and Morris and is common to most adsorption processes, was also tested [50]. This functional relationship can be expressed as the following linear equation [39]:

$$
q_{\mathrm{t}}=k_{\mathrm{id}} t^{0.5}+C
$$

where $k_{\mathrm{id}}$ is the intraparticle diffusion rate constant $\left(\mathrm{mg} \mathrm{g}^{-1}\right.$ $\min ^{-0.5}$ ), and $C$ is the intercept, which represents the thickness of the boundary layer.

Fig. $5 \mathrm{c}$ shows the Weber-Morris plots for the kinetic model of MO adsorption at different initial MO concentrations; two linear regions were observed for all of the initial concentrations. This result indicates that the adsorption of $\mathrm{MO}$ onto the nanofibrous mat is affected by more than one process, not only by intraparticle diffusion. According to a previous report, the first linear region represents diffusion of the adsorbate through the solution to the external surface of the adsorbent (film diffusion), and the second linear section corresponds to the diffusion of the adsorbate from the external surface to the internal pores of the adsorbent, which is called intraparticle diffusion [41]. Moreover, there is no line passing through the origin, which also reveals that intraparticle diffusion was not the only rate-controlling step in the entire adsorption process [39]. The $\mathrm{k}_{\mathrm{id}, 1}$ and $\mathrm{k}_{\mathrm{id}, 2}$ values calculated using the intraparticle diffusion kinetics model are listed in Table 2 . The $k_{\mathrm{id}, 1}$ values are greater than the $k_{\mathrm{id}, 2}$ values, which suggests that film diffusion is an important step in adsorption of $\mathrm{MO}$ onto the $\mathrm{m}-\mathrm{PEI} / \mathrm{PVDF}$ nanofibrous mat. Both $k_{\mathrm{id}, 1}$ and $k_{\mathrm{id}, 2}$ increase with increasing initial MO concentration owing to the growing effect of diffusion as the driving force at both the external and internal surfaces of the adsorbent.

\section{Adsorption isotherm}

The adsorption isotherms of MO onto the m-PEI/PVDF nanofibrous mats were investigated using the Langmuir and Freundlich isotherm models, which are expressed by the following equations [42]:

$$
\begin{gathered}
\frac{C_{\mathrm{e}}}{q_{\mathrm{e}}}=\frac{1}{b q_{\mathrm{m}}}+\frac{C_{\mathrm{e}}}{q_{\mathrm{m}}}, \\
\ln q_{\mathrm{e}}=\ln K_{\mathrm{F}}+\frac{1}{n} \ln C_{\mathrm{e}},
\end{gathered}
$$

respectively, where $q_{\mathrm{e}}\left(\mathrm{mg} \mathrm{g}^{-1}\right)$ is the amount of $\mathrm{MO}$ adsorbed at equilibrium, $C_{\mathrm{e}}\left(\mathrm{mg} \mathrm{L}^{-1}\right)$ is the equilibrium concentration of $\mathrm{MO}$ in solution, $q_{\mathrm{m}}\left(\mathrm{mg} \mathrm{g}^{-1}\right)$ is the maximum adsorption capacity, $b\left(\mathrm{~L} \mathrm{mg}^{-1}\right)$ is the Langmuir constant related to the adsorption energy, and $K_{\mathrm{F}}$ and $n$ are the Freundlich constants, which represent the adsorption capacity and adsorption intensity, respectively.

The Langmuir and Freundlich isotherm parameters are listed in Table 3, and the plots are shown in Fig. 6. As we know, the Langmuir adsorption isotherm model assumes that adsorption occurs at a specific homogeneous range of sites within the adsorbent on a monolayer surface and no interaction occurs between adsorbed species, so it is suitable for physical adsorption [47]. In contrast, the Freundlich isotherm generally describes adsorption occurring on a heterogeneous adsorbent surface that has unequal available sites with different adsorption energies; it can be applied to physical adsorption and chemical adsorption [47]. The correlation coefficient of the Langmuir isotherm is clearly much higher than that of the Freundlich isotherm in Table 3, and the maximum adsorption capacity of $\mathrm{MO}$ calculated by the Langmuir model is $625 \mathrm{mg} \mathrm{g}^{-1}$, which is very close to the experimental maximum adsorption capacity $\left(633 \mathrm{mg} \mathrm{g}^{-1}\right)$. Therefore, the Langmuir isotherm

\begin{tabular}{|c|c|c|c|c|c|}
\hline \multicolumn{3}{|c|}{ Langmuir model } & \multicolumn{3}{|c|}{ Freundlich model } \\
\hline$q_{\mathrm{m}, \mathrm{cal}}\left(\mathrm{mg} \mathrm{g}^{-1}\right)$ & $b$ & $R^{2}$ & $K_{\mathrm{F}}$ & $n$ & $R^{2}$ \\
\hline 625 & 0.03831 & 0.98778 & 94.561 & 3.2113 & 0.83507 \\
\hline
\end{tabular}
model, which describes physical adsorption on a monolayer surface with homogeneous adsorption, is more suitable

Table 3 Langmuir and Freundlich isotherm parameters for adsorption of MO onto electrospun m-PEI/PVDF nanofibrous mats 

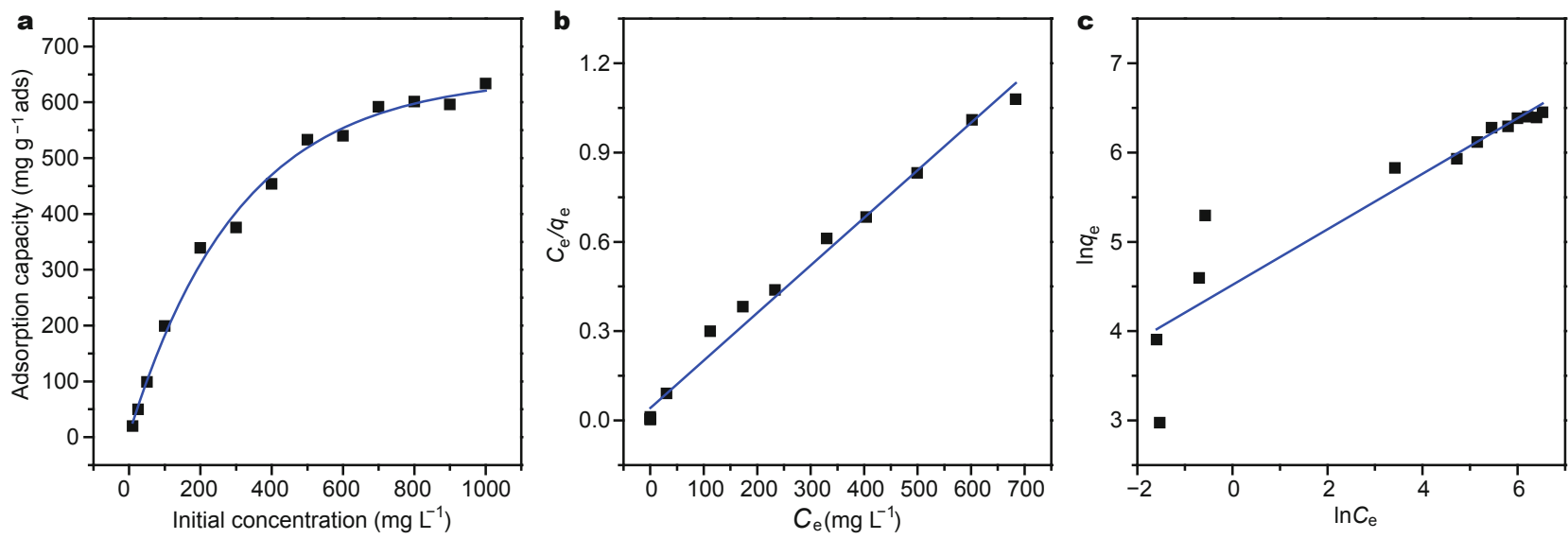

Figure 6 Adsorption capacity in $\mathrm{MO}$ solutions with different initial concentrations (adsorbent dosage: $0.5 \mathrm{~g} \mathrm{~L}^{-1}$, temperature: $25^{\circ} \mathrm{C}$, time: $24 \mathrm{~h}$, $\mathrm{pH} 7$ ) linear plots of (b) Langmuir and (c) Freundlich isotherm models for MO adsorption onto m-PEI/PVDF nanofibrous mats.

for describing the MO adsorption behavior onto m-PEI/ PVDF nanofibrous mats.

\section{CONCLUSIONS}

Composite nanofibrous mats with nanoscale, porous structure were successfully prepared by electrospinning a methacrylated b-PEI and PVDF mixture solution. Further, the composite mats can remove an anionic dye (MO) effectively from aqueous solution; they showed an excellent maximum adsorption capacity of $633 \mathrm{mg} \mathrm{g}^{-1}$ for $\mathrm{MO}$ and retained good adsorption ability after being reused 10 times. A batch adsorption experiment confirmed that the adsorption performance of the m-PEI/PVDF nanofibrous mats was affected by the temperature, initial concentration, and $\mathrm{pH}$ value of the MO solution. The pseudo-second-order kinetic model is more appropriate for describing the adsorption behavior of MO onto the mats because of its higher correlation coefficient values $\left(\mathrm{R}^{2}>0.998\right)$ and calculated equilibrium adsorption capacities that are closer to the experimental results for $\mathrm{MO}$ at different initial concentrations. Kinetic analysis using the intraparticle diffusion model demonstrates that adsorption of MO onto the nanofibrous mat is affected by more than one process, including at least film diffusion and intraparticle diffusion. Further, film diffusion is an important step in adsorption of $\mathrm{MO}$ onto the m-PEI/PVDF nanofibrous mat. An investigation of the adsorption isotherms demonstrates that the Langmuir isotherm is more suitable for describing MO adsorption onto the m-PEI/PVDF nanofibrous mats. This work indicates that the $\mathrm{m}-\mathrm{PEI} / \mathrm{PVDF}$ nanofibrous mats could potentially be used as an adsorbent for removal of anionic dyes in wastewater treatment, and it is also expected to inspire the preparation of high-performance nanofibrous functional materials by electrospinning.

Received 1 January 2016; accepted 20 January 2016; published online 29 January 2016

1 Wang M, Webber M, Finlayson B, et al. Rural industries and water pollution in china. J Environ Manage, 2008, 86: 648-659

2 Zhang XJ, Chen C, Lin PF, et al. Emergency drinking water treatment during source water pollution accidents in China: origin analysis, framework and technologies. Environ Sci Technol, 2011, 45: $161-167$

3 Jiang Y. China's water security: current status, emerging challenges and future prospects. Environ Sci Policy, 2015, 54: 106-125

4 Lin J, Ye W, Huang J, et al. Toward resource recovery from textile wastewater: dye extraction, water and base/acid regeneration using a hybrid NF-BMED process. ACS Sustain Chem Eng, 2015, 3: 1993-2001

5 Sponza DT. Toxicity studies in a chemical dye production industry in turkey. J Hazard Mater, 2006, 138: 438-447

6 Suryavathi V, Sharma S, Sharma S, et al. Acute toxicity of textile dye wastewaters (untreated and treated) of sanganer on male reproductive systems of albino rats and mice. Reprod Toxicol, 2005, 19: 547-556

7 Ahmad A, Mohd-Setapar SH, Chuong CS, et al. Recent advances in new generation dye removal technologies: novel search for approaches to reprocess wastewater. RSC Adv, 2015, 5: 30801-30818

8 Zhao H, Jiao T, Zhang L, et al. Preparation and adsorption capacity evaluation of graphene oxide-chitosan composite hydrogels. Sci China Mater, 2015, 58: 811-818

9 Yagub MT, Sen TK, Afroze S, et al. Dye and its removal from aqueous solution by adsorption: a review. Adv Colloid Interface Sci, 2014, 209: 172-184

10 Yu Y, Zhang B, Yu M, et al. High-selective removal of ultra-low level mercury ions from aqueous solution using oligothymonucleic acid functionalized polyethylene film. Sci China Chem, 2012, 55: 2202-2208

11 Xing Z, Hu J, Wang M, et al. Properties and evaluation of amidoxime-based uhmwpe fibrous adsorbent for extraction of uranium from seawater. Sci China Chem, 2013, 56: 1504-1509

12 Zhang H, Goeppert A, Prakash GKS, et al. Applicability of linear polyethylenimine supported on nano-silica for the adsorption of $\mathrm{CO}_{2}$ from various sources including dry air. RSC Adv, 2015, 5: 
$52550-52562$

13 Tang Z, Han Z, Yang G, et al. Polyethylenimine loaded nanoporous carbon with ultra-large pore volume for $\mathrm{CO}_{2}$ capture. Appl Surf Sci, 2013, 277: 47-52

14 Liu J, Liu Y, Wu Z, et al. Polyethyleneimine functionalized protonated titanate nanotubes as superior carbon dioxide adsorbents. J Colloid Interface Sci, 2012, 386: 392-397

15 Sehaqui H, Gálvez ME, Becatinni V, et al. Fast and reversible direct $\mathrm{CO}_{2}$ capture from air onto all-polymer nanofibrillated cellulosepolyethylenimine foams. Environ Sci Technol, 2015, 49: 3167-3174

16 Wang S, Li Z, Lu C. Polyethyleneimine as a novel desorbent for anionic organic dyes on layered double hydroxide surface. J Colloid Interface Sci, 2015, 458: 315-322

17 Qiu WZ, Yang HC, Wan LS, et al. Co-deposition of catechol/polyethyleneimine on porous membranes for efficient decolorization of dye water. J Mater Chem A, 2015, 3: 14438-14444

18 Wang X, Min M, Liu Z, et al. Poly(ethyleneimine) nanofibrous affinity membrane fabricated via one step wet-electrospinning from poly(vinyl alcohol)-doped poly(ethyleneimine) solution system and its application. J Membrane Sci, 2011, 379: 191-199

19 Min M, Shen L, Hong G, et al. Micro-nano structure poly(ether sulfones)/poly(ethyleneimine) nanofibrous affinity membranes for adsorption of anionic dyes and heavy metal ions in aqueous solution. Chem Eng J, 2012, 197: 88-100

20 Li D, Xia Y. Electrospinning of nanofibers: reinventing the wheel? Adv Mater, 2004, 16: 1151-1170

21 Chen $\mathrm{Z}$, Zhao J, Yang $\mathrm{X}$, et al. Fabrication of $\mathrm{TiO}_{2} / \mathrm{WO}_{3}$ composite nanofibers by electrospinning and photocatalystic performance of the resultant fabrics. Ind Eng Chem Res, 2016, 55: 80-85

22 Singh P, Mondal K, Sharma A. Reusable electrospun mesoporous $\mathrm{ZnO}$ nanofiber mats for photocatalytic degradation of polycyclic aromatic hydrocarbon dyes in wastewater. J Colloid Interface Sci, 2013, 394: 208-215

23 Pant B, Barakat NAM, Pant HR, et al. Synthesis and photocatalytic activities of $\mathrm{CdS} / \mathrm{TiO}_{2}$ nanoparticles supported on carbon nanofibers for high efficient adsorption and simultaneous decomposition of organic dyes. J Colloid Interface Sci, 2014, 434: 159-166

24 Liu C, Hsu PC, Lee HW, et al. Transparent air filter for high-efficiency PM2.5 capture. Nat Commun, 2015, 6: 6205

25 Wang Y, Li W, Xia Y, et al. Electrospun flexible self-standing $\gamma$-alumina fibrous membranes and their potential as high-efficiency fine particulate filtration media. J Mater Chem A, 2014, 2: 15124-15131

26 Li X, Wang N, Fan G, et al. Electreted polyetherimide-silica fibrous membranes for enhanced filtration of fine particles. J Colloid Interface Sci, 2015, 439: 12-20

27 Xie SY, Liu XY, Zhang BW, et al. Electrospun nanofibrous adsorbents for uranium extraction from seawater. J Mater Chem A, 2015, 3: $2552-2558$

$28 \mathrm{Xu} \mathrm{X,} \mathrm{Zhang} \mathrm{JF,} \mathrm{Fan} \mathrm{Y.} \mathrm{Fabrication} \mathrm{of} \mathrm{cross-linked} \mathrm{polyethylene-}$ imine microfibers by reactive electrospinning with in situ photo-cross-linking by UV radiation. Biomacromolecules, 2010, 11: 2283-2289

29 Rutledge GC, Lowery JL, Pai CL. Characterization by mercury porosimetry of nonwoven fiber media with deformation. J Eng Fiber Fabr, 2009, 4: 1-13

30 Lowery JL, Datta N, Rutledge GC. Effect of fiber diameter, pore size and seeding method on growth of human dermal fibroblasts in electrospun poly( $\varepsilon$-caprolactone) fibrous mats. Biomaterials, 2010, 31: 491-504

31 Zhu X, Cui W, Li X, et al. Electrospun fibrous mats with high porosity as potential scaffolds for skin tissue engineering. Biomacromolecules, 2008, 9: 1795-1801

32 Yang YF, Wan LS, Xu ZK. Surface hydrophilization of microporous polypropylene membrane by the interfacial crosslinking of polyethylenimine. J Membrane Sci, 2009, 337: 70-80

33 Chen C, Yang ST, Ahn WS, et al. Amine-impregnated silica monolith with a hierarchical pore structure: enhancement of $\mathrm{CO}_{2}$ capture capacity. Chem Commun, 2009, 45: 3627-3629

34 Patel PA, Eckart J, Advincula MC, et al. Rapid synthesis of polymer-silica hybrid nanofibers by biomimetic mineralization. Polymer, 2009, 50: 1214-1222

35 Demirci S, Sahiner N. The use of metal nanoparticle-embedded poly(ethyleneimine) composite microgel in the reduction of nitrophenols. Water Air Soil Poll, 2015, 226: 64

36 Zhang DN, Kou KC, Gao P, et al. Preparation and characterization of PTFE-g-GMA modified PTFE/SiO $\mathrm{S}_{2}$ organic-inorganic hybrids. J Polym Res, 2012, 19: 1-10

37 Li J, Christensen L, Obrovac M, et al. Effect of heat treatment on Si electrodes using polyvinylidene fluoride binder. J Electrochem Soc, 2008, 155: A234-A238

38 Santos C, Silva CJ, Buttel Z, et al. Preparation and characterization of polysaccharides/PVA blend nanofibrous membranes by electrospinning method. Carbohyd Polym, 2014, 99: 584-592

39 Ai LH, Zhang CY, Meng LY. Adsorption of methyl orange from aqueous solution on hydrothermal synthesized $\mathrm{Mg}$-Al layered double hydroxide. J Chem Eng Data, 2011, 56: 4217-4225

40 Liu Y, Cui G, Luo C, et al. Synthesis, characterization and application of amino-functionalized multi-walled carbon nanotubes for effective fast removal of methyl orange from aqueous solution. RSC Adv, 2014, 4: 55162-55172

41 Chen S, Zhang J, Zhang C, et al. Equilibrium and kinetic studies of methyl orange and methyl violet adsorption on activated carbon derived from phragmites australis. Desalination, 2010, 252: 149-156

42 Sarkar C, Bora C, Dolui SK. Selective dye adsorption by $\mathrm{pH}$ modulation on amine-functionalized reduced graphene oxide-carbon nanotube hybrid. Ind Eng Chem Res, 2014, 53: 16148-16155

43 Kou T, Wang Y, Zhang C, et al. Adsorption behavior of methyl orange onto nanoporous core-shell $\mathrm{Cu} @ \mathrm{Cu}_{2} \mathrm{O}$ nanocomposite. Chem Eng J, 2013, 223: 76-83

44 Tanhaei B, Ayati A, Lahtinen M, et al. Preparation and characterization of a novel chitosan $/ \mathrm{Al}_{2} \mathrm{O}_{3} /$ magnetite nanoparticles composite adsorbent for kinetic, thermodynamic and isotherm studies of methyl orange adsorption. Chem Eng J, 2015, 259: 1-10

45 Liu Y, Luo C, Sun J, et al. Enhanced adsorption removal of methyl orange from aqueous solution by nanostructured proton-containing $\delta-\mathrm{MnO}_{2}$. J Mater Chem A, 2015, 3: 5674-5682

$46 \mathrm{Wu} \mathrm{Y}$, Zhang M, Zhao H, et al. Functionalized mesoporous silica material and anionic dye adsorption: MCM-41 incorporated with amine groups for competitive adsorption of acid fuchsine and acid orange II. RSC Adv, 2014, 4: 61256-61267

47 Ma Q, Shen F, Lu X, et al. Studies on the adsorption behavior of methyl orange from dye wastewater onto activated clay. Desalin Water Treat, 2013, 51: 3700-3709

48 Chen H, Dai G, Zhao J, et al. Removal of copper(II) ions by a biosorbent-cinnamomum camphora leaves powder. J Hazard Mater, 2010, 177: 228-236

49 Zhou J, Tang C, Cheng B, et al. Rattle-type carbon-alumina coreshell spheres: synthesis and application for adsorption of organic dyes. ACS Appl Mater Interfaces, 2012, 4: 2174-2179

50 Weber WJ, Morris JC. Kinetics of adsorption on carbon from solution. J Sanit Eng Div Am Soc Civ Eng, 1963, 89: 31-60

Acknowledgements This work was supported by the National Natural Science Foundation of China (51473183, 11305248 and 11305241).

Author contributions Zhang B and Li J designed and supervised the project; Ma Y performed the material preparation; Ma Y and Yu M con- 
ducted the material characterization; $\mathrm{Ma} \mathrm{Y}$ and $\mathrm{Ma} \mathrm{H}$ carried out the adsorption experiments; Zhang B, Ma Y and Li L analyzed the data; Ma Y, Zhang B and Li J wrote the manuscript. All authors contributed to the general discussion and reviewed this manuscript.

Conflict of interest The authors declare that they have no conflict of interest.
Supplementary information The calibration curve of concentration in MO standard solution $v s$. absorbance at $464 \mathrm{~nm}$ in UV-vis spectra, effect of solution $\mathrm{pH}$ value to $\mathrm{MO}$ adsorption capacity of nanofibrous mat and the plot of $\ln k v s .1 / T$ for calculation of activation energy. And one video showing the desorption process of MO adsorbed nanofibrous mat in $\mathrm{NaOH}$ solution. These information details are available in the online version of the paper.

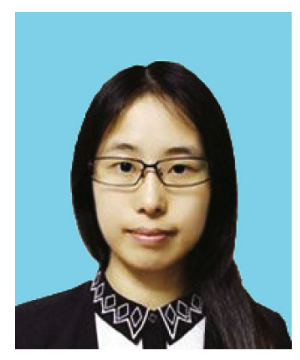

Yao Ma is currently a PhD candidate at Shanghai Institute of Applied Physics, Chinese Academy of Sciences, under the supervision of Prof. Jingye Li. Her research interest is mainly focused on the fabrication of functional nanofibrous materials by electrospinning and radiation technique and their application in wastewater treatment and drinking water purification.

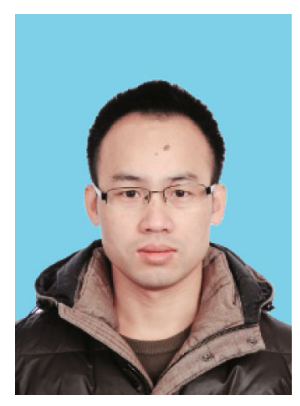

Bowu Zhang obtained his PhD degree in 2012 under the supervision of Prof. Jingye Li from Shanghai Institute of Applied Physics, Chinese Academy of Sciences. And then he joined in the group of Prof. Jingye Li as an associate researcher. His recent research interest focuses on the functional nanocarbon materials and polymer materials for water relevant application.

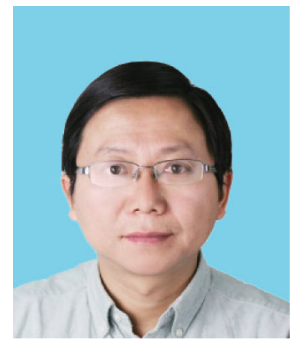

Jingye Li obtained his PhD degree in polymer materials in 2002, under the supervision of Prof. Deyue Yan at Shanghai Jiao Tong University. After that, he began his research career focusing on the functional polymeric materials by radiation induced graft polymerization at Waseda University, Japan. From 2007, he became a full professor at Shanghai Institute of Applied Physics, Chinese Academy of Sciences. His research interest is developing novel materials by radiation techniques.

\section{聚乙烯亚胺纳米纤维吸附剂用于高效吸附水溶液中的阴离子型染料}

马圭, 张伯武, 马红娟, 虞鸣, 李林繁, 李景烨

摘要 本文通过静电纺丝法将聚甲基丙酸缩水甘油酯(GMA)修饰的支化聚乙烯亚胺(b-PEI), 即改性PEI(m-PEI)与聚偏氟乙烯(PVDF)混合溶液 制成m-PEI/PVDF纳米复合纤维毡, 并用于吸附去除水溶液中阴离子型染料. 通过SEM、 米级, 且纤维毡为多孔状, 表面带正电荷, 具有吸附阴离子型污染物的性能特征. 通过研究其对阴离子染料一甲基橙(MO)的吸附性能, 我们发现 该吸附剂可快速从水溶液中去除甲基橙且最大吸附容量达 $633.3 \mathrm{mg} \mathrm{g}^{-1}$, 大大优于已报道的相关吸附剂. 而且, 该吸附剂在 $\mathrm{NaOH}$ 溶液中浸泡可 快速再生, 表现出良好的重复利用性. 本文进一步研究了温度、初始浓度和溶液 $\mathrm{pH}$ H直对甲基橙在该吸附剂上的吸附行为的影响, 并证明该吸附 剂吸附甲基橙的行为符合准二级动力学模型和Langmuir吸附等温模型. Weber-Morris模型则表明甲基橙吸附到m-PEI/PVDF纳米纤维毡的过 程, 受液膜扩散和颗粒内扩散的控制. 此研究结果表明, m-PEI/PVDF纳米纤维毡有望应用于处理含阴离子染料或污染物的废水. 